\title{
Numerical simulation on effect of irrigation conditions on water temperature distribution in a paddy field
}

\author{
Kazuhiro Nishida $^{1}$ (D) Shuichiro Yoshida ${ }^{2} \cdot$ Sho Shiozawa $^{2}$
}

Received: 1 September 2021 / Revised: 24 November 2021 / Accepted: 29 November 2021 / Published online: 1 January 2022

(c) The Author(s) 2021

\begin{abstract}
Water management methods regulate water temperature in paddy fields, which affects rice growth and the environment. To understand the effect of irrigation conditions on water temperature in a paddy field, water temperature distribution under 42 different irrigation models including the use of ICT water management, which enables remote and automatic irrigation, was simulated using a physical model of heat balance. The following results were obtained: (1) Irrigation water temperature had a more significant effect on paddy water temperature close to the inlet. As the distance from the inlet increased, the water temperature converged to an equilibrium, which was determined by meteorological conditions and changes in water depth. (2) Increasing the irrigation rate with higher irrigation water amount increased the extent and magnitude of the effects of the irrigation water temperature. (3) When total irrigation water amount was the same, increasing the irrigation rate decreased the time-averaged temperature gradient effect over time across the paddy field. (4) Irrigation during the lowest and highest paddy water temperatures effectively decreased and increased the equilibrium water temperature, respectively. The results indicate that irrigation management can be used to alter and control water temperature in paddy fields, and showed the potential of ICT water management in enhancing the effect of water management in paddy fields. Our results demonstrated that a numerical simulation using a physical model for water temperature distribution is useful for revealing effective water management techniques under various irrigation methods and meteorological conditions.
\end{abstract}

Keywords Water management $\cdot$ Paddy water temperature $\cdot$ Heat balance equation $\cdot$ Numerical simulation $\cdot$ ICT water management systems · Flowing irrigation

\section{Introduction}

The water temperature in a rice paddy field has a significant impact on the growth, yield, and quality of the crop (Shimono et al. 2002; Sharifi et al. 2018) and on the surrounding environment by influencing nitrogen discharge and greenhouse gas emissions (Rizzo et al. 2014; Tan et al. 2018). Because the water temperature of paddy fields can be controlled to some extent through water management methods (Nishida et al. 2015, 2016; Mitsuyasu et al. 2020), the

Kazuhiro Nishida

nishidak971@affrc.go.jp

1 Institute for Rural Engineering, National Agriculture and Food Research Organization, 2-1-6 Kannondai, Tsukuba, Ibaraki 305-8609, Japan

2 Department of Biological and Environmental Engineering, The University of Tokyo, 1-1-1 Yayoi, Bunkyo-ku, Tokyo 113-8657, Japan application of such techniques to control the paddy water temperature may improve rice quality and yield while reducing excess nitrogen discharge and greenhouse gas emissions. In recent years in Japan, the use of water management systems based on information and communication technologies (ICT), that is, ICT water management systems, which enable automation and remote control of irrigation and drainage in a field, have been increasingly adopted (Wakasugi and Suzuki 2017). Because the use of such systems enables the implementation of those water management techniques that were previously difficult to implement, such as midnight irrigation and frequent short-duration irrigation, it is expected to facilitate more efficient irrigation management.

Various water management techniques have been used in Japan to control water temperature, preventing cold- and high-temperature damage in paddy rice (Wada 1992; Morita et al. 2016). For example, in recent years, water management techniques such as flowing irrigation and controlling water depth have been used (Tomosho and Yamashita 2009) to 
prevent or reduce high-temperature damage to rice plants (Tashiro and Wardlaw 1991) caused by high air temperatures during the rice grain ripening period (Terashima et al. 2001; Morita 2008; Morita et al. 2016). In particular, low-temperature flowing irrigation, which introduces and simultaneously drains water from the outlet of paddy fields to cool paddy water temperature (Nishida et al. 2021), is believed to be the most effective method (Tomosho and Yamashita 2009), and its effect on reducing the high-temperature damage to rice has been studied (Nagahata et al. 2005; Miyasaka et al. 2011; Wada et al. 2013). However, because the application of such water management techniques often requires more water than conventional water management techniques (Nishida et al. 2016), it may invite water-use problems (Tomosho and Yamashita 2009). Because future climate change is predicted to increase high-temperature damage to rice (Morita 2008), development of water management conditions (e.g., irrigation rate, timing, water depth, duration, and interval) that minimize water consumption while optimizing temperature of the paddy environment is essential.

Several field experiments have been conducted to understand the effect of irrigation conditions on paddy water temperature and determine optimal management conditions (Nishida et al. 2015, 2016; Mitsuyasu et al. 2020). These studies indicate that irrigation forms a water temperature gradient in a paddy field, and this gradient is significant under flowing irrigation (Nishida et al. 2015, 2016). The gradient changes depending on irrigation rate and timing (Nishida et al. 2015, 2016), and the daily range of water temperature changes with water depth (Mitsuyasu et al. 2020).

Although these previous studies demonstrated the effect of water management techniques on the water temperature, the data required for understanding optimal water management are still limited. In particular, because the use of ICT water management systems is very recent, research on its effects has just begun (Suzuki et al. 2020), and thus, its effective use is not yet known. Additionally, water management experiments in paddy fields require considerable time and labor, making it difficult to obtain sufficient data on water temperature. Furthermore, differences in field and meteorological conditions make it difficult to compare the effects of different irrigation conditions on water temperature in field experiments.

To this end, numerical simulations are useful for examining the effect of irrigation conditions on paddy water temperature. They can be used to compare the effects under exactly the same field and meteorological conditions. Various models of temperature in paddy fields have been developed to understand and predict water balance, evapotranspiration, and temperature in paddy fields (e.g., Inoue 1985; Kondo and Watanabe 1992; Kim et al. 2001; Saptomo et al. 2004; Yoshida et al. 2013; Maruyama et al. 2017; Liu et al. 2019). In recent years, to simulate the effect of water management on water temperature distribution, Nishida et al. (2021) developed a numerical model that can predict the water temperature distribution considering the heat exchange between the atmosphere-rice, atmosphere-water, and water-soil, as well as the horizontal heat advection in paddy fields. It has been shown that this model can reproduce the water temperature distribution under flowing irrigation with high accuracy, which cannot be expressed by conventional numerical methods (Nishida et al. 2021). However, although model development and validation have been previously conducted by Nishida et al. (2021), numerical simulations using the model to quantitatively investigate the difference in water temperature distribution under different irrigation and water management conditions were not conducted. Therefore, the effect of irrigation conditions and water management methods on water temperature distribution remains unclear. As there have been no attempts to simulate the effects of irrigation conditions on water temperature distribution in a paddy field to date, numerical simulations using this model are useful for understanding optimal and effective irrigation conditions for water temperature control.

The objective of this study was to investigate the effect of irrigation conditions on water temperature distribution in paddy fields using numerical simulations. Different irrigation temperatures, rates, timings, intervals, and durations were simulated, and their effects on water temperature distribution were compared and discussed.

\section{Material and methods}

\section{Numerical model}

The model proposed by Nishida et al. (2021) was used for numerical simulations. The authors showed that this model can reproduce the water temperature distribution under flowing irrigation with high accuracy. (Root mean square error of the water temperature during the entire validation period and nighttime flowing irrigation was 0.98 and $0.55{ }^{\circ} \mathrm{C}$, respectively.) This model consists of three parts: (1) calculation of horizontal water movement in a paddy field, (2) calculation of the temperature distribution of water and rice, and (3) calculation of soil temperature. The governing equations and numerical procedures are summarized in Appendices A and $\mathrm{B}$, respectively.

\section{Water management conditions}

Fourteen water management conditions with different rates, intervals, durations, and timings were simulated (Table 1). Conventional water management (intermittent irrigation with half-day irrigation or continuous irrigation) and ICT water management (short-duration irrigation) were 


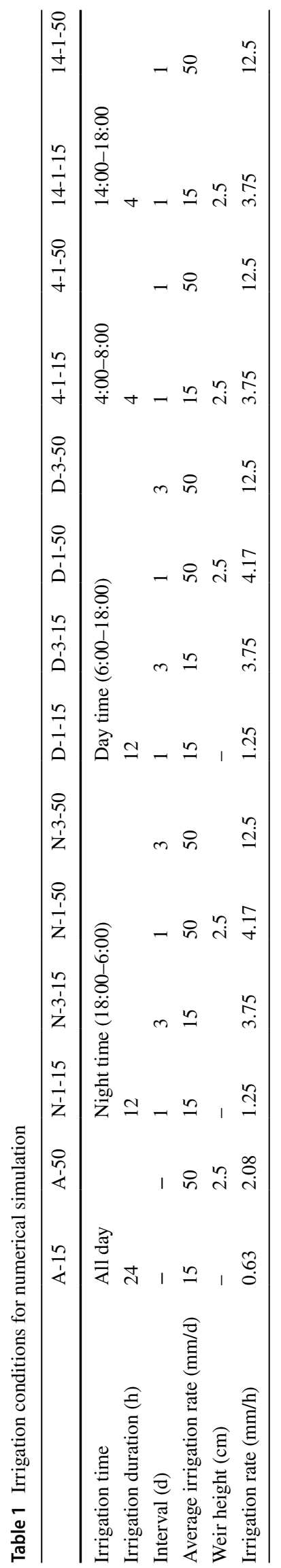

considered. Furthermore, use of normal irrigation, which has no surface runoff from the outlet, versus flowing irrigation, which uses a larger amount of irrigation water and has surface runoff, was also considered.

The irrigation conditions for intermittent irrigation were as follows: irrigation time of $12 \mathrm{~h}$ at night (18:00-6:00) or daytime (6:00-18:00); irrigation interval of every 1 or 3 days; average irrigation rate during the whole period of $15 \mathrm{~mm} \mathrm{~d}^{-1}$ (normal irrigation), which is almost the same as the total of the evapotranspiration rate and deep percolation rate as determined from preliminary calculations, or $50 \mathrm{~mm}$ $\mathrm{d}^{-1}$ (flowing irrigation). These cases are referred to as irrigation time ( $\mathrm{N}$ or $\mathrm{D})$, interval ( 1 or 3 ), and average irrigation rate (15 or 50 ; Table 1$)$. For example, nighttime irrigation every 3 days with $50 \mathrm{~mm} \mathrm{~d}^{-1}$ was referred to as N-3-50.

Water management conditions for continuous irrigation were as follows: average irrigation rate of 15 or $50 \mathrm{~mm} \mathrm{~d}^{-1}$. These cases were referred to as A-15 and A-50, respectively (Table 1).

Water management conditions for short-duration irrigation were as follows: irrigation time of $4 \mathrm{~h}$ at pre-dawn (4:00-8:00) or midday (14:00-18:00); daily irrigation interval; average irrigation rate of 15 and $50 \mathrm{~mm} \mathrm{~d}^{-1}$. These cases are referred to as the start of irrigation time (4 or 14), interval (1), and average irrigation rate (15 or 50) (Table 1). For example, irrigation at 4:00-8:00 every 1 day with $50 \mathrm{~mm} \mathrm{~d}^{-1}$ is referred to as 4-1-50.

For intermittent irrigation and short-time irrigation, the irrigation rate increases with an increase in irrigation interval or decrease in irrigation duration, even when the average irrigation rate ( $=$ total irrigation water amount) is the same (Table 1). For example, irrigation rates of N-3-50 and 4-1-50 were equivalent to $12.5 \mathrm{~mm} \mathrm{~h}^{-1}$ and were threefold that of $\mathrm{N}-1-50$, at $4.17 \mathrm{~mm} \mathrm{~h}^{-1}$.

\section{Irrigation water temperature}

To determine the effect of irrigation water temperature on the water temperature distribution, three irrigation water temperature cases were considered.

Case 1: low irrigation water temperature $\left(19.2-22.1^{\circ} \mathrm{C}\right)$; average daily water temperature changes measured in an irrigation canal adjacent to a paddy field, described in the next section (Fig. 1a).

Case 2: high water temperature; irrigation water temperature is always $10^{\circ} \mathrm{C}$ higher than that of Case 1 .

Case 3: The irrigation water temperature does not affect the water temperature distribution (water temperature in a paddy field is spatially uniform); the irrigation water temperature is the same as the paddy water temperature.

Under these 42 conditions ( 14 water management conditions $\times 3$ irrigation water temperature conditions), the water temperature distribution for 12 days was calculated. Since 


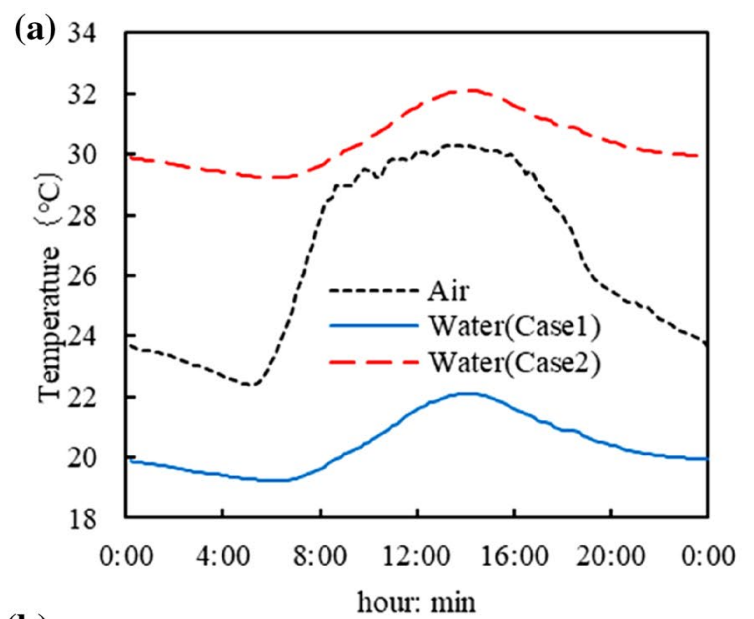

(b)

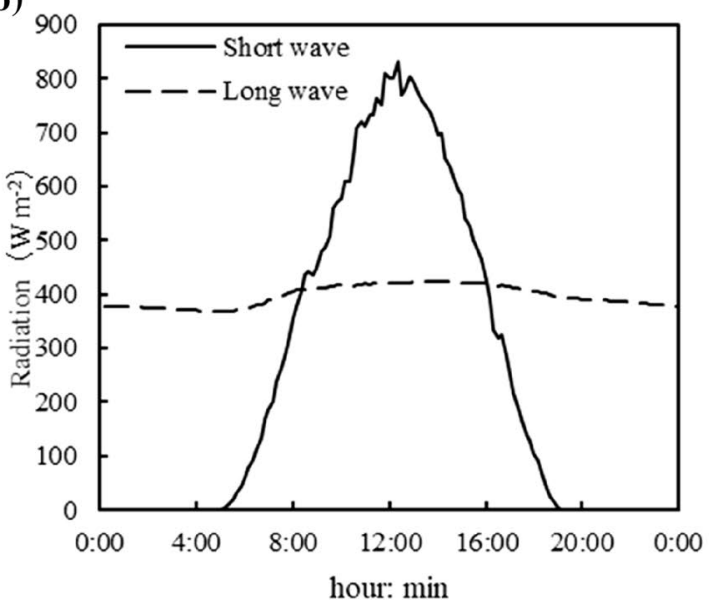

(c)

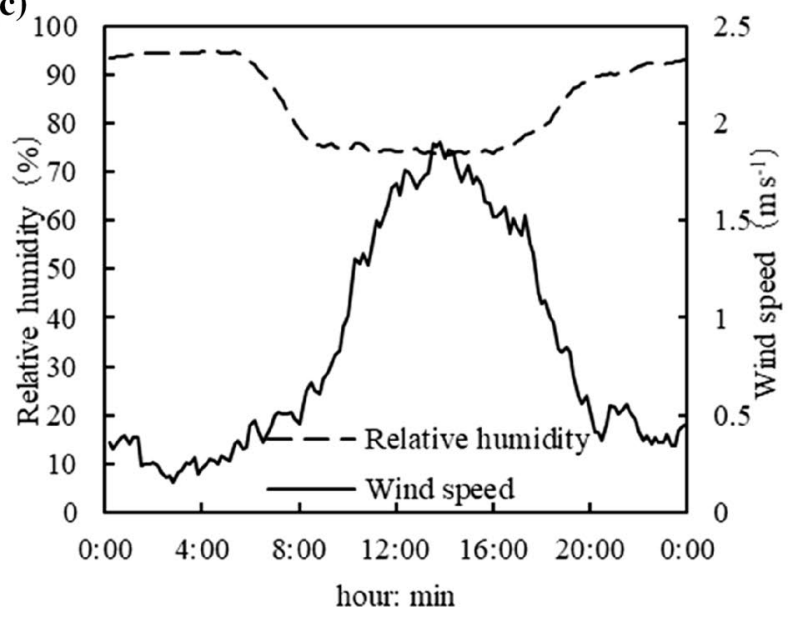

Fig. 1 Meteorological and irrigation water temperature conditions for numerical simulation. a Irrigation water temperature of Cases 1 and 2, and air temperature, b downward short and long wave radiation, and $\mathbf{c}$ wind speed and relative humidity

the water temperature few days following the start of water management is affected by the initial condition, to reduce the effect of initial condition and simplify the analysis, the time-averaged water temperature distributions on the 0:00 of
Table 2 Soil, rice, and paddy field properties used for the simulation

\begin{tabular}{ll}
\hline Surface albedo & 0.2 \\
Heat capacity & $3.43 \times 10^{6} \mathrm{Jm}^{-3} \mathrm{~K}^{-1}$ \\
Heat conductivity of soil, $l$ & $1 \mathrm{Wm}^{-1} \mathrm{~K}^{-1}$ \\
Vegetation height, $h_{\mathrm{c}}$ & $1 \mathrm{~m}$ \\
Leaf area index, LAI & 4 \\
Transmissivity of vegetation for radia- & $0.165(=\exp (-0.45 \times \mathrm{LAI}))$ \\
$\quad$ tion, $f_{\mathrm{v}}$ & Estimated (Maruyama and \\
Stomatal conductance & Kuwagata 2008) \\
& $10 \mathrm{~mm} \mathrm{~d}{ }^{-1}$ \\
Percolation rate, $\mathrm{P}$ & $100 \mathrm{~m}$ \\
Paddy length, $\mathrm{L}$ & $30 \mathrm{~m}$ \\
Paddy width & $0.017352 \mathrm{~m}^{0.5} \mathrm{~s}^{-1}$ \\
Empirical constant, a in Eq. (6) &
\end{tabular}

the 10th to 24:00 of the 12th days, when the effect of initial temperatures on water temperature distribution had almost disappeared, were calculated and compared.

\section{Data used for numerical simulation}

The meteorological conditions used for the simulations are shown in Fig. 1. The data are the average value of the observation data for 20 days (August 2-21) after the heading date of rice determined from field observation, during which time the average air temperature is known to have a positive correlation with high-temperature damage of rice (Morita 2008; Morita et al. 2016), measured in a paddy field in Hakusan City, Ishikawa Prefecture, Japan, in 2015. The downward long-wave radiation from the sky was estimated from air temperature and humidity using the equations of Kondo (1994). In the calculations, the meteorological conditions (Fig. 1) were repeated daily.

The soil, rice, and paddy field properties required for the simulation are summarized in Table 2. The time step $\Delta t$ was set to $10 \mathrm{~s}$, the horizontal space node was set to 21 points $(n x=21)$, and the vertical space node was set to six points $(n z=6)$. Initial water and soil temperature, and bottom boundary soil temperature were set as $26.5^{\circ} \mathrm{C}$. The initial water depth was $2.5 \mathrm{~cm}$. Weir height of the outlet of flowing irrigation was $2.5 \mathrm{~cm}$.

\section{Results}

\section{Changes in water depth}

Figure 2 shows examples of changes in water depth and irrigation rate, indicating that changes in water depth show various patterns owing to the difference in water management conditions. Overall, the average water depth under flowing irrigation $\left(50 \mathrm{~mm} \mathrm{~d}^{-1}\right)$ was higher than that under normal 
(a)

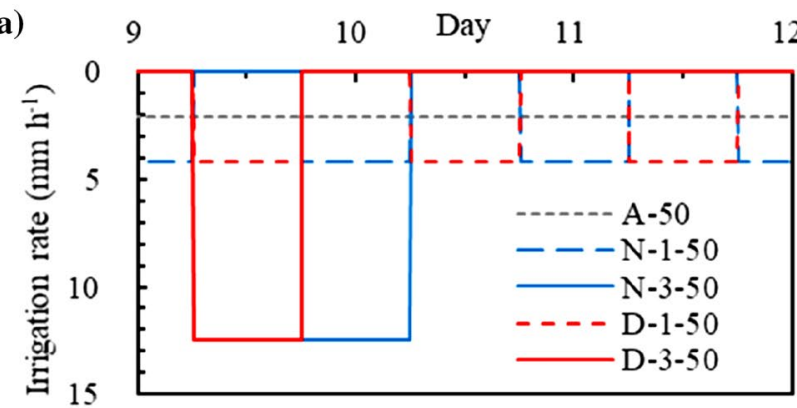

(c)

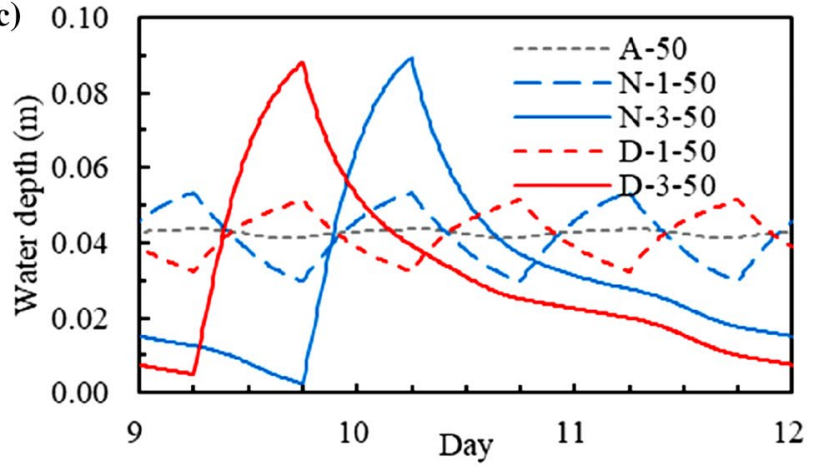

12 (b)

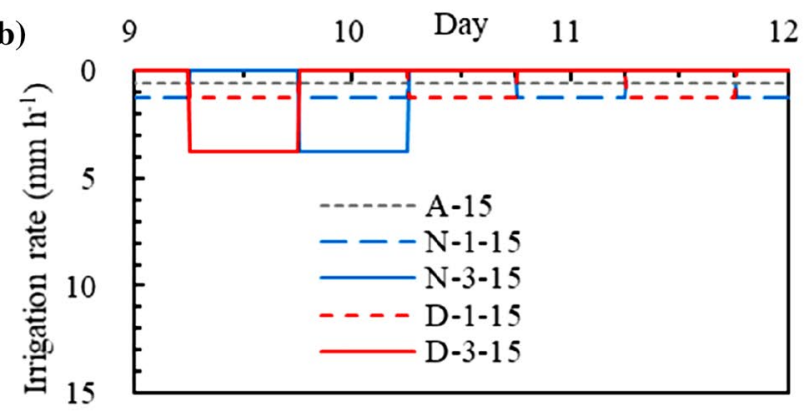

(d) 0.10

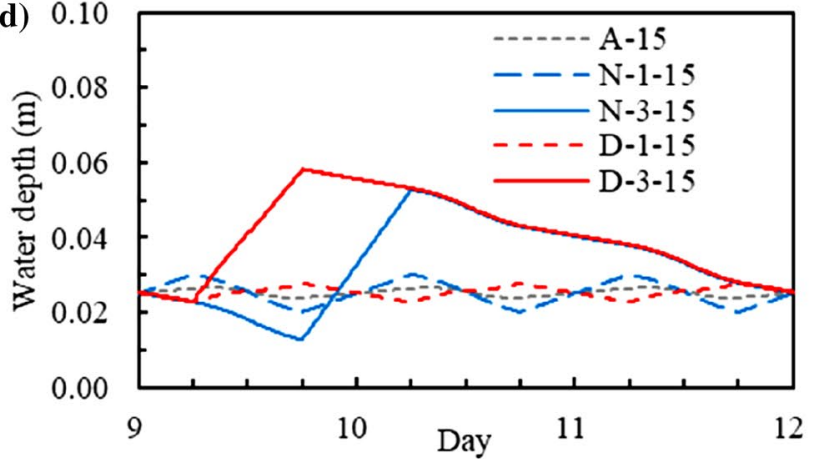

Fig. 2 Examples of $(\mathbf{a}, \mathbf{b})$ irrigation conditions and $(\mathbf{c}, \mathbf{d})$ changes in water depth

irrigation $\left(15 \mathrm{~mm} \mathrm{~d}^{-1}\right)$ and fluctuation ranges in water depth, that is, maximum-minimum water depth, increased with irrigation rate during irrigation by lengthening the irrigation interval and shortening irrigation duration. Nighttime and daytime irrigation increased water depth during nighttime and daytime, respectively.

\section{Changes in water temperature}

Figure 3 shows examples of changes in water temperatures over time in the paddy fields of Cases 1,2, and 3. The results of all irrigation conditions are shown in Online Resource (Fig. S1, S2, and S3). The results indicate that water temperature varied significantly depending on the conditions of irrigation water management.

The common trends were as follows: (1) A water temperature gradient was formed in the paddy field due to irrigation. In Case 1, water temperature close to the inlet was lower. In Case 2, on the other hand, water temperature became higher as it was closer to the inlet, except in 14-1-15 and 14-1-50. (2) The difference in water temperature between Cases 1 and 2 was large near the inlet; however, it gradually decreased with distance from the inlet (example time changes in water temperature of three cases are shown in Fig. 4). Outlet temperatures were nearly identical in all the three cases. (3) The water temperature gradient decreased with time after the end of irrigation. The water temperature difference in the paddy field almost disappeared by the start of the next irrigation under the long interval irrigation conditions (e.g., N-3-50 and D-3-50). (4) The water temperature difference was larger under flowing irrigation than under normal irrigation.

\section{Average water temperature distribution}

The time-averaged water temperature distributions of all numerical simulations are shown in Fig. 5. Using these temperature distributions, the effects of irrigation water temperature and management conditions on the water temperature distribution were compared and investigated.

\section{Effect of irrigation water temperature on water temperature distribution}

Each part of Fig. 5 compares the average water temperature distributions for Cases 1, 2, and 3. Under all irrigation conditions, Case 2 had a higher average water temperature than Case 1. The water temperature difference between cases was larger closer to the inlet and became smaller farther from the inlet. The average water temperature for Cases 1 and 2 gradually approached the water temperature of Case 3 as the distance from the inlet increased.

\section{Effect of irrigation rate on water temperature distribution}

The average water temperatures under flowing irrigation $\left(50 \mathrm{~mm} \mathrm{~d}^{-1}\right)$ were lower and higher than those under normal 
(a)

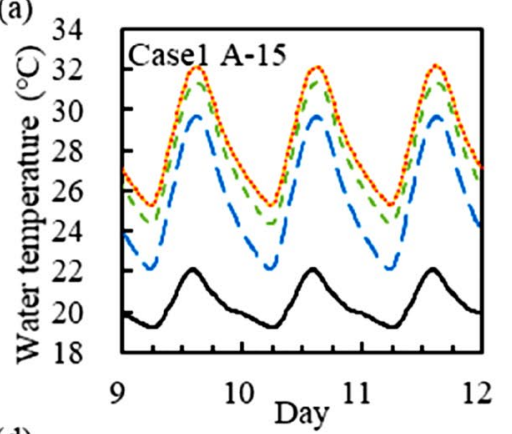

(d)
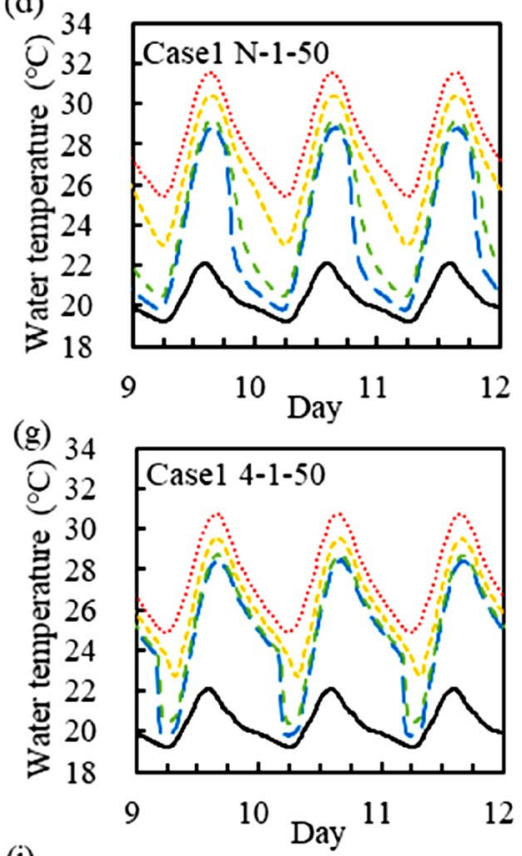

(j)
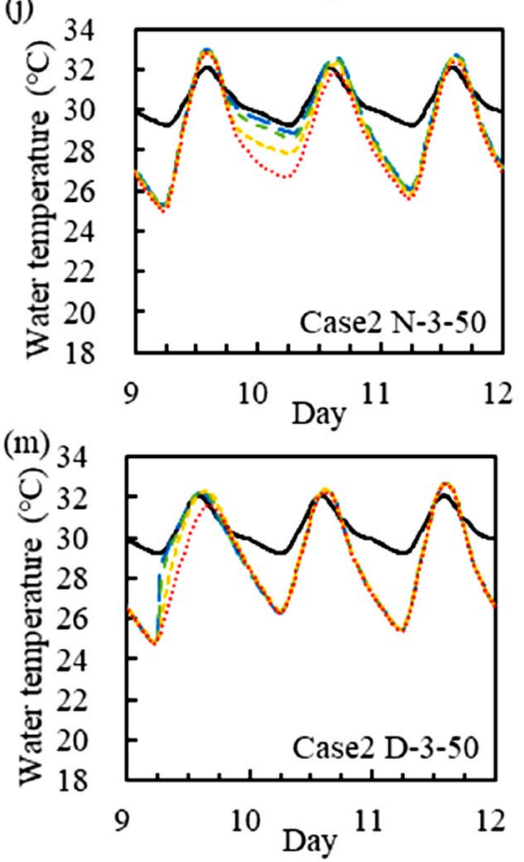

(b)

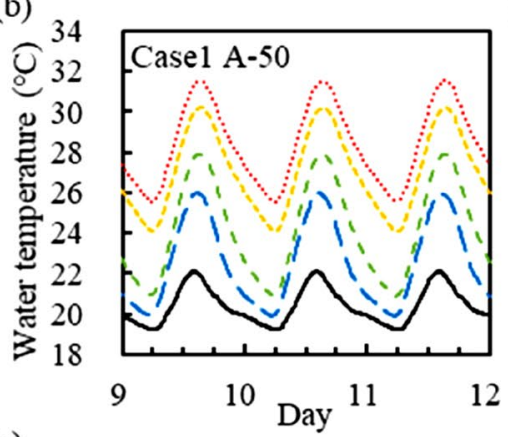

(e)

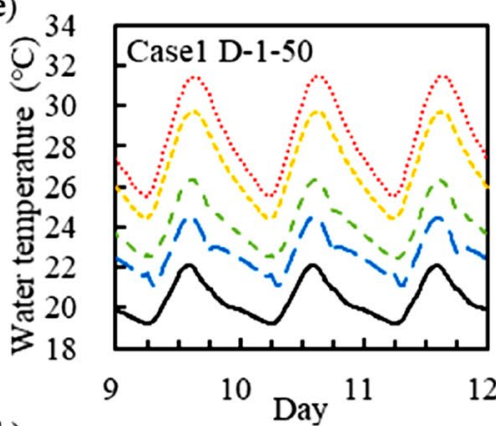

(h) 34

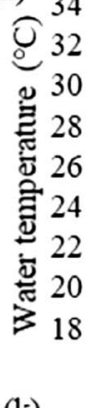

(k)

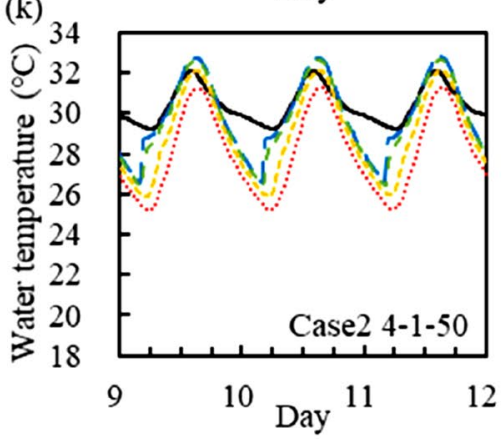

(c)

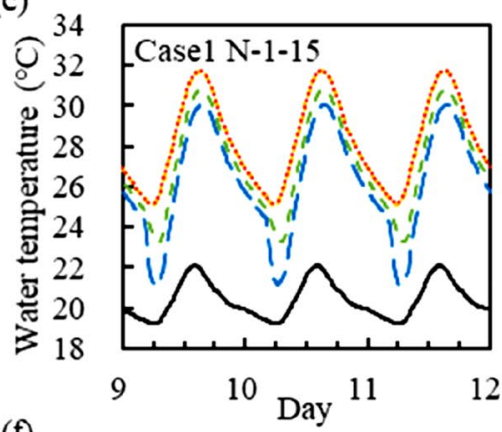

(f)
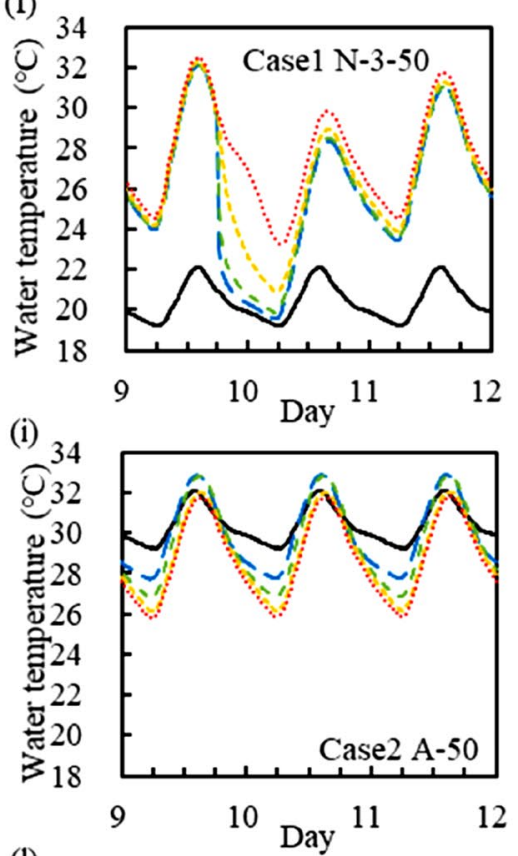

(l)

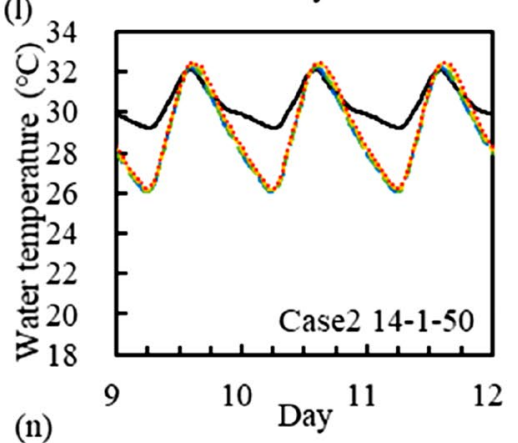

(n)

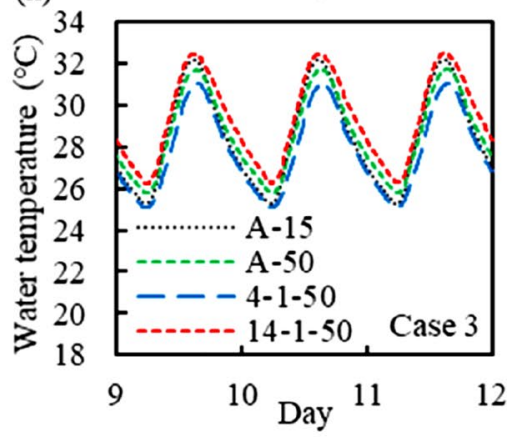

Fig. 3 Changes in water temperature at 10, 20, 50, and $100 \mathrm{~m}$ from the inlet of the paddy field. a-h: Case 1, i-m Case 2, n Case 3. Lines indicate distance from the inlet $(\mathbf{m})$ 
(a)

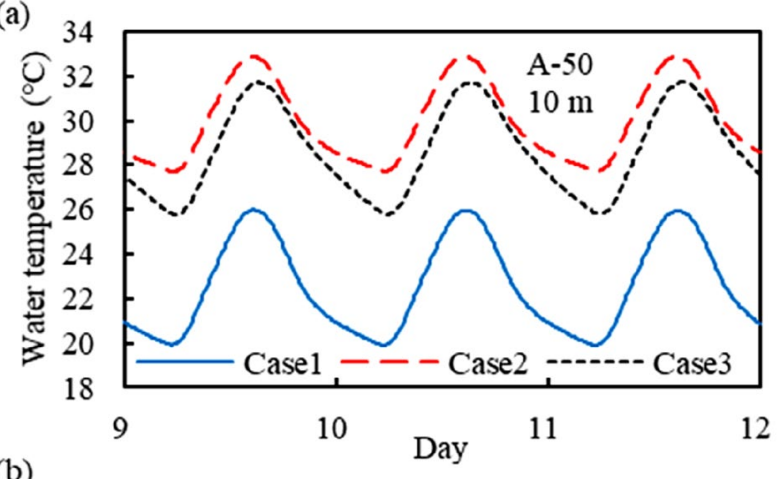

(b)

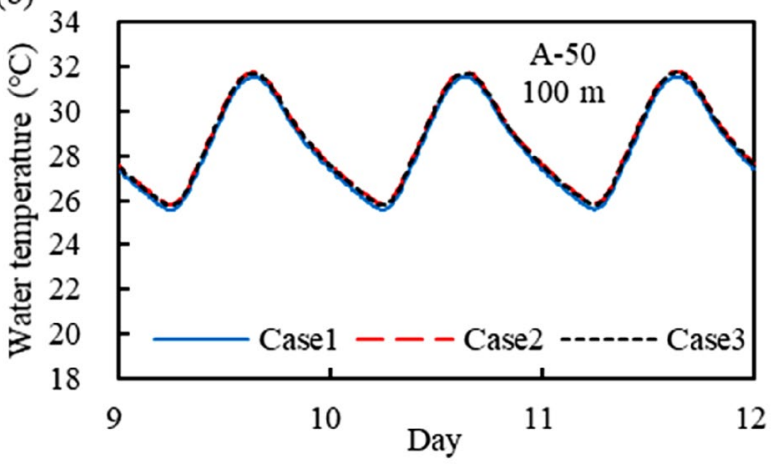

Fig. 4 Comparison of water temperature over time for A-50 a $10 \mathrm{~m}$ from the inlet, and $\mathbf{b} 100 \mathrm{~m}$ from the inlet (outlet)

conditions $\left(15 \mathrm{~mm} \mathrm{~d}^{-1}\right)$ for Case 1 and Case 2 , respectively (Fig. 5). Under normal irrigation, the water temperature difference between the three cases was large near the inlet, but was small or almost nonexistent near the outlet. The distance at which the water temperature was almost the same was approximately $50 \mathrm{~m}$ from the inlet. This result indicates that the effect of irrigation water temperature on paddy water temperature is limited to the inlet area under normal irrigation. On the other hand, for flowing irrigation, a water temperature difference was observed up to the outlet. The comparison of water temperature distribution indicates that flowing irrigation with high irrigation rate effectively increases the effect of irrigation water temperature on paddy water temperature.

\section{Effect of irrigation interval on water temperature distribution}

The average water temperature distributions under different average irrigation intervals are compared in Fig. 6. As the irrigation interval increased, the temperature difference between the three cases became smaller near the inlet; however, it became larger far from the inlet. These results indicate that long-interval irrigation, which increases irrigation rate, homogenizes water temperature in a paddy field.
Figure 7 compares the time average water temperature on the first, second, and third day after the start of irrigation with N-3-50. The water temperature gradients in the N-3-50 fields on the first, second, and third day were lower than those in the N-1-50 fields. The average water temperature of N-3-50 on day 1 of the interval was lower than that of $\mathrm{N}-1-50$, while that on days 2 and 3 was higher near the inlet and lower near the outlet than that of N-1-50. Because the average water temperature near the outlet of $\mathrm{N}-3-50$ on day 1 was lower than that of $\mathrm{N}-1-50$, the 3-day average water temperature of N-3-50 also became lower than that of N-1-50. Conversely, because the average water temperature near the inlet of $\mathrm{N}-3-50$ on day 1 was lower, but that on the days 2 and 3 was higher than that of N-150 , the 3-day average water temperature of $\mathrm{N}-3-50$ was higher than that of $\mathrm{N}-1-50$.

\section{Effect of irrigation time on water temperature distribution}

Figure 8 compares the average water temperature distributions under nighttime and daytime irrigation. For both Case 1 and Case 2, the water temperature near the inlet was lower during daytime irrigation than during nighttime irrigation, but the opposite was observed near the outlet. The water temperatures for Case 3 were slightly lower under nighttime irrigation than under daytime irrigation; however, the difference was quite minimal, although the changes in water depth over time were different (Fig. 2).

Figure 9 compares the average water temperatures under short-duration irrigation. Water temperatures for Case 3 for flowing irrigation and normal irrigation were 1.5 and $0.5{ }^{\circ} \mathrm{C}$ higher under midday irrigation than under pre-dawn irrigation, respectively (Table 3 ). Similarly, the water temperatures near the outlet for Case 1 and Case 2 were higher under midday irrigation than under pre-dawn irrigation. This result indicates that the water temperature near the outlet can be controlled by changing the irrigation timing under short-duration irrigation.

Figure $10 \mathrm{a}$ and $\mathrm{b}$ compares the water temperature and depth trends of Case 3 under 4-1-50 and 14-1-50. The water temperature of 4-1-50 was always $1.2-1.9{ }^{\circ} \mathrm{C}$ lower than that of 14-1-50. The water depth of 4-1-50 was higher than that of 14-1-50 around pre-dawn to midday; however, it was lower from around midday to pre-dawn. A comparison of Fig. 10a and $b$ indicates that the water depths of 14-1-50 and 4-1-50 increased when the water temperature started to decrease and increase, respectively. This result suggests that irrigation during the time of lowest or highest paddy water temperature decreases or increases the equilibrium water temperature, respectively. 

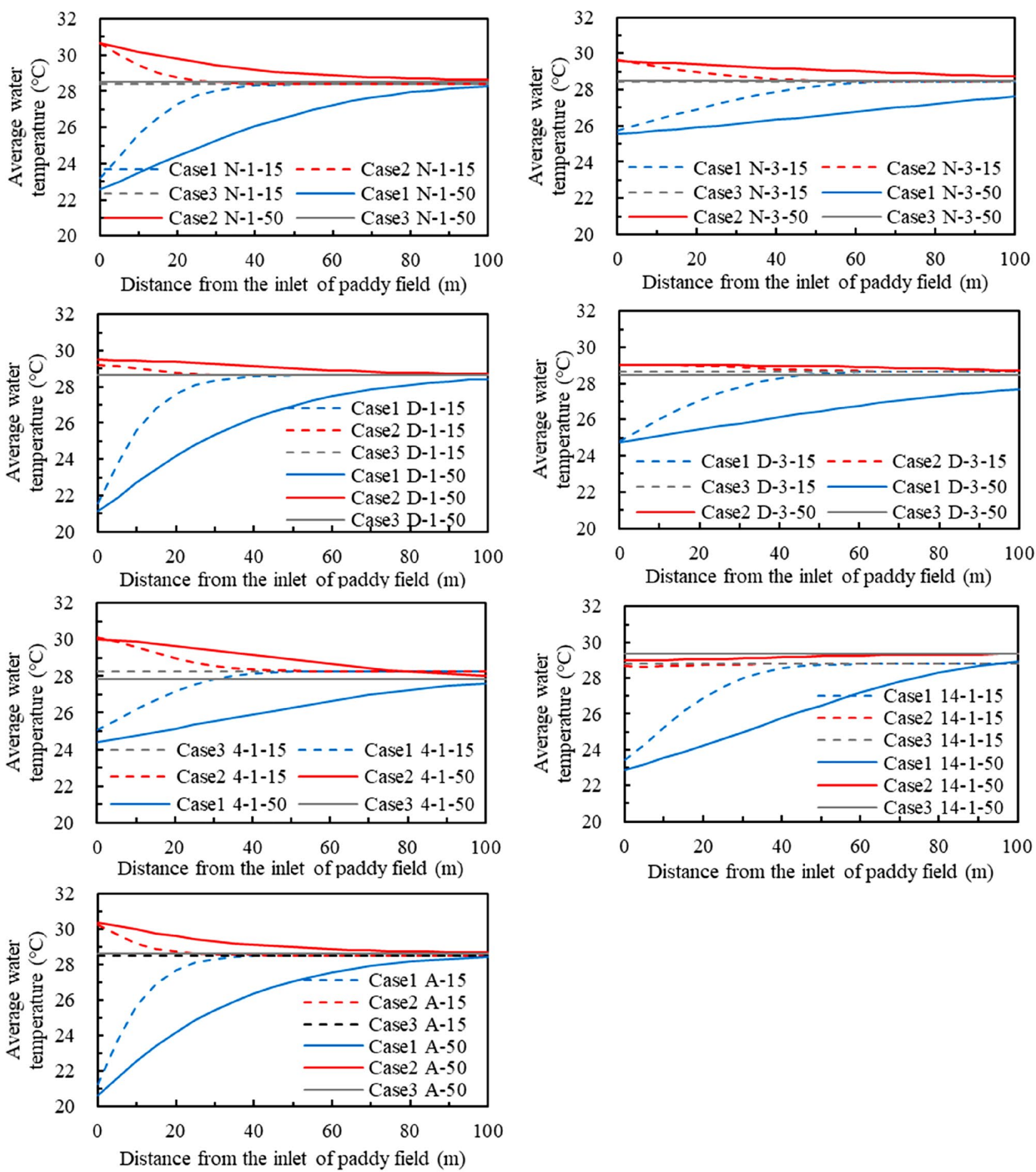

Fig. 5 Average water temperature distribution (paddy field length [inlet to outlet] is $100 \mathrm{~m}$ )

\section{Spatial average, maximum, and minimum of time-averaged water temperature}

Table 3 summarizes the spatial average, maximum, and minimum time-averaged water temperatures for the 42 cases.
The spatial average water temperature for Cases 1,2 , and 3 ranged from 26.2-27.9, 28.6-29.2, and 27.9-29.4 ${ }^{\circ} \mathrm{C}$, respectively. The maximum temperature values for Cases 1 and 2 ranged from 27.6-28.9 and 28.8-30.7, respectively, and the minimum values ranged from $20.6-25.7{ }^{\circ} \mathrm{C}$ and $28.0-29.0$ 

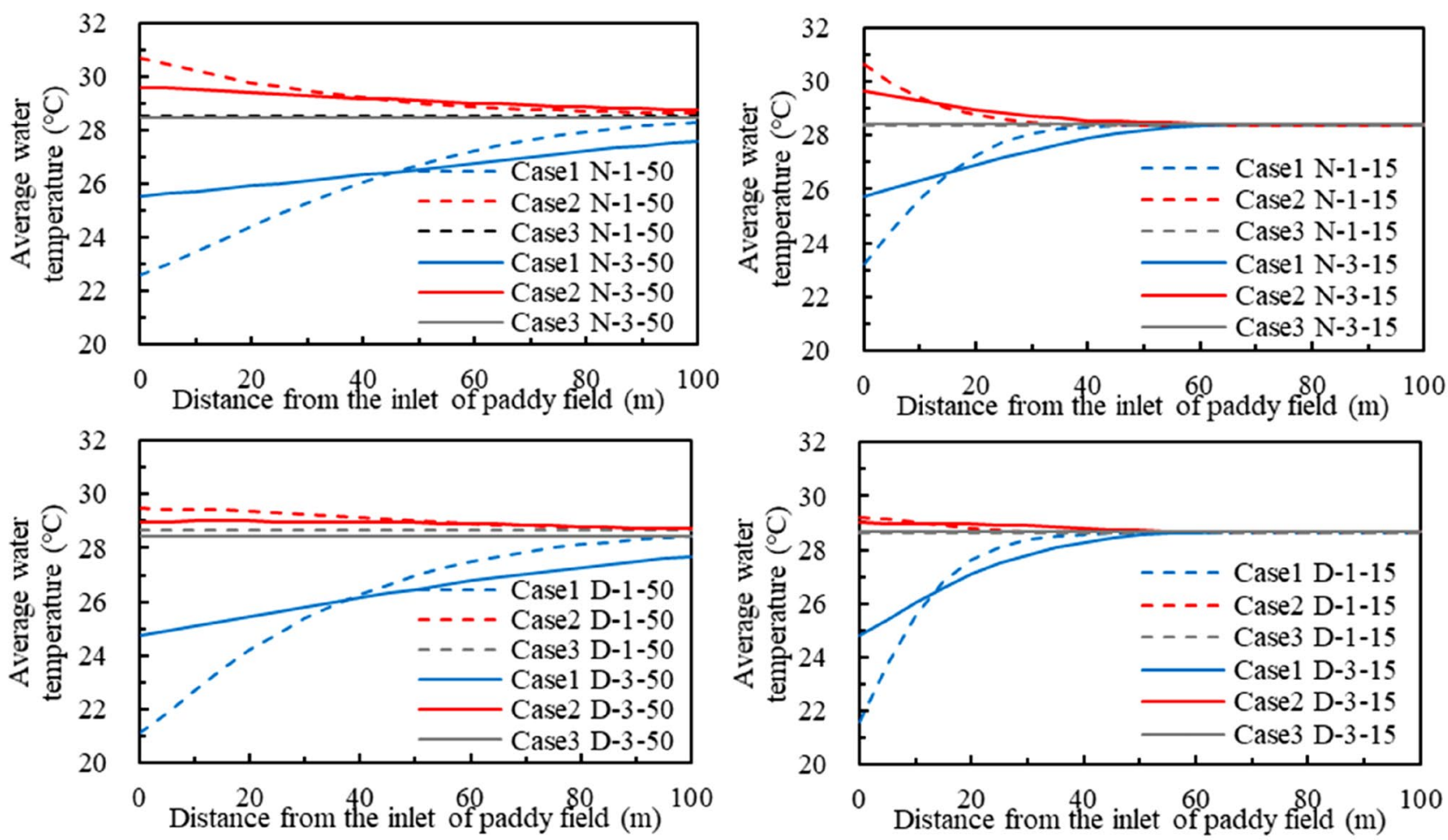

Fig. 6 Comparison of water temperature distribution under 1-day and 3-day irrigation intervals

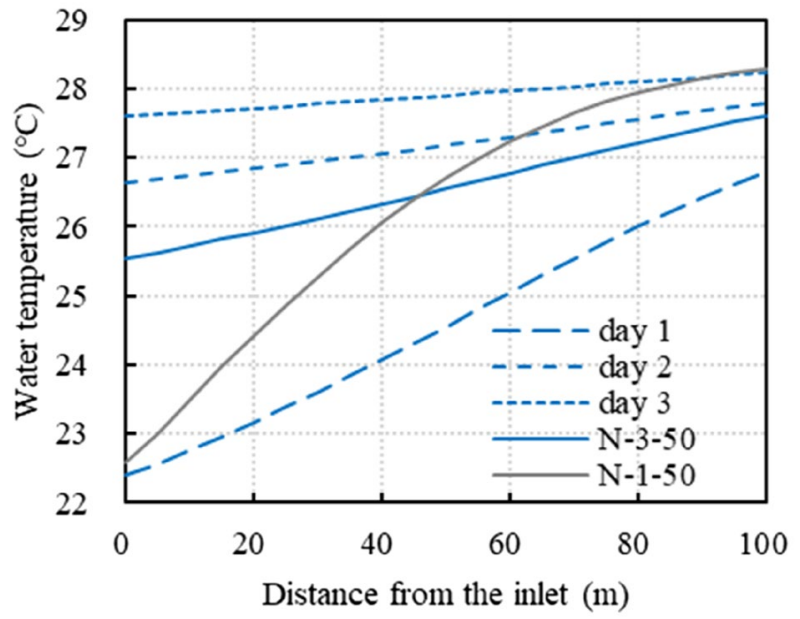

Fig. 7 Comparison of average water temperatures on the first, second, and third day after the start of irrigation of N-3-50

${ }^{\circ} \mathrm{C}$, respectively. The temperature variation within a paddy field, that is, the spatial maximum-minimum water temperature, for Cases 1 and 2 ranged from $2.1-7.8^{\circ} \mathrm{C}$ and $0.2-2.3$, respectively. No temperature variations were observed for Case 3. For all water management models, the spatial average, maximum, and minimum temperatures were larger for Case 2 than for Case 1, indicating the significant influence of irrigation water temperature on those temperatures.
However, the variation of water temperatures in the same case indicated that fluctuations can occur due to differences in water management even under the same irrigation water temperature.

The water management conditions for the lowest and highest water temperatures differed depending on the irrigation water temperature. For example, the spatial average water temperature was lowest in 4-1-50 for Case 1, in 4-115 for Case 2, and in 4-1-50 for Case 3, and was highest in 14-1-15 for Case 1, in N-1-50 for Case 2, and 14-1-50 for Case 3. These results indicate that the water management conditions that most effectively control paddy field temperature significantly depend on the irrigation water temperature.

\section{Discussion}

\section{Formation of water temperature distribution}

In a paddy field, because irrigation water is heated or cooled through heat exchange with the atmosphere, rice canopy, and soil as it flows through the field, a water temperature gradient from the inlet to the outlet is inevitably formed (Nishida et al. 2018, 2021). Our numerical simulation clearly demonstrated that water temperature fluctuations and distributions were affected by irrigation water temperature and management conditions, even under the same meteorological 

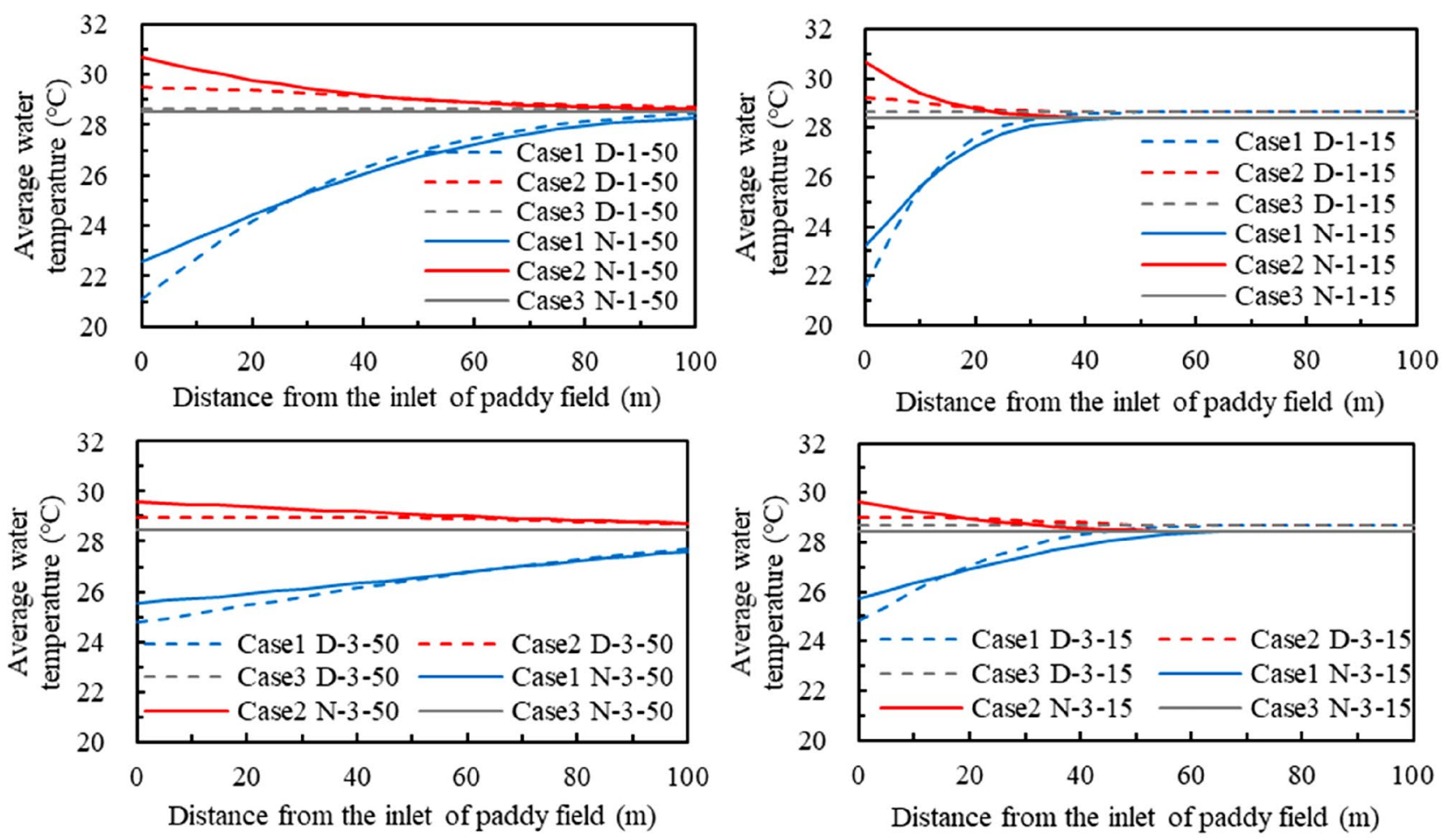

Fig. 8 Comparison of water temperature distribution under nighttime and daytime irrigation
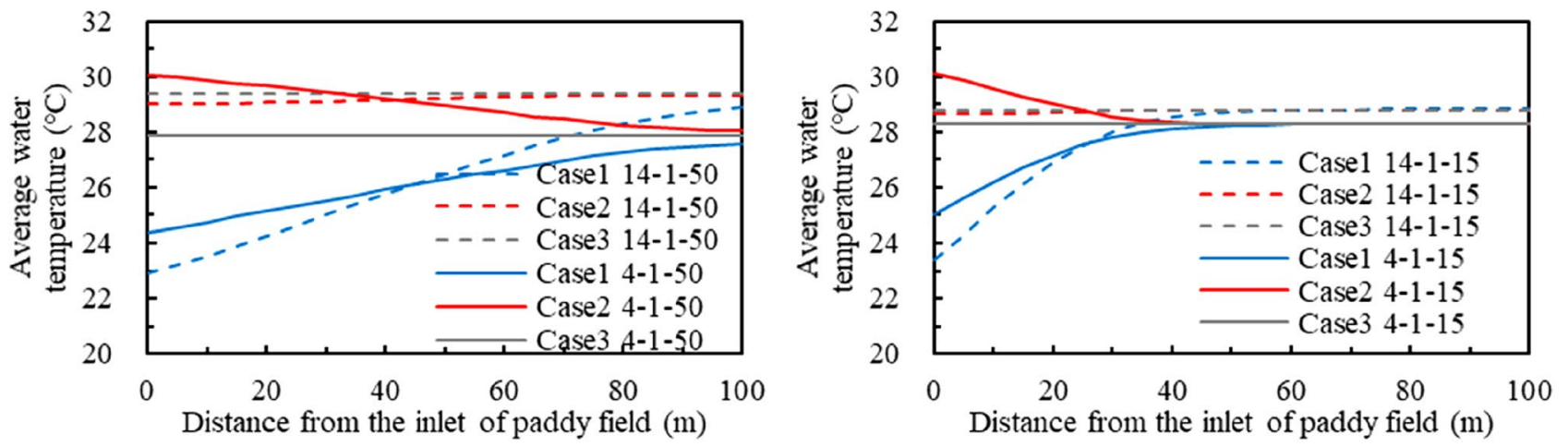

Fig. 9 Comparison of water temperature distribution under 4-h irrigation at 4:00 and at 14:00

conditions (Figs. 3 and 5). The difference in water temperature distributions in our simulation confirms that irrigation water temperature and management must be considered to accurately understand and control the water temperature environment in a paddy field.

A comparison of the water temperature distributions for Cases 1, 2, and 3 showed that the water temperature differences among the cases were largest at the inlet, but gradually decreased and eventually disappeared as the distance from the inlet increased (Fig. 5). This result indicates that (1) there is an equilibrium water temperature that is determined not by irrigation water temperature but by changes in water depth and meteorological conditions; (2) when the irrigation water temperature is different from the equilibrium water temperature, a temperature gradient is formed in a paddy field by irrigation.

These results indicate that the effect of water management on water temperature distribution can be understood by two mechanisms: inflow of irrigation water, which controls the water temperature distribution, and changes in water depth, which determine the equilibrium water temperature. 


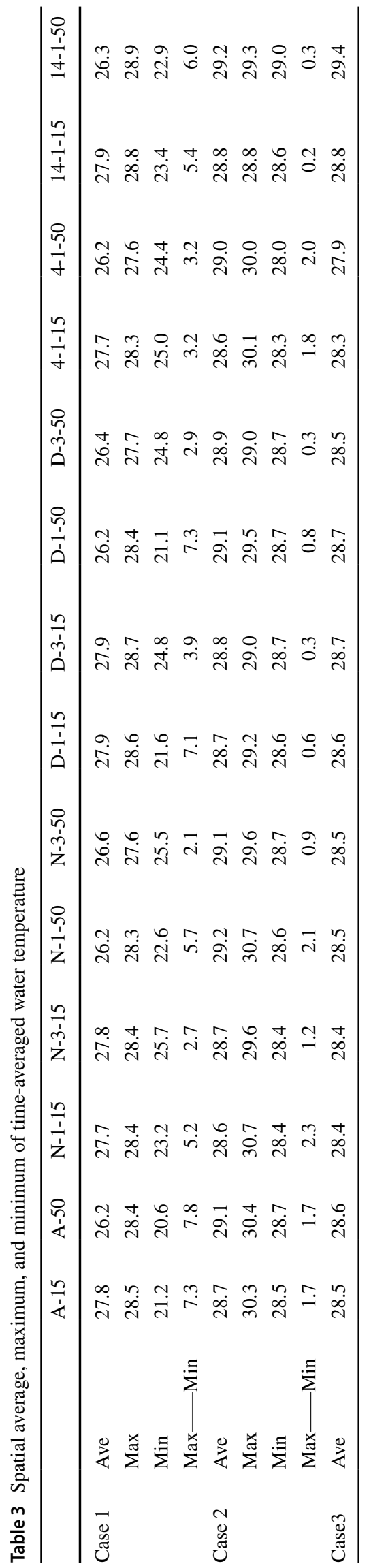

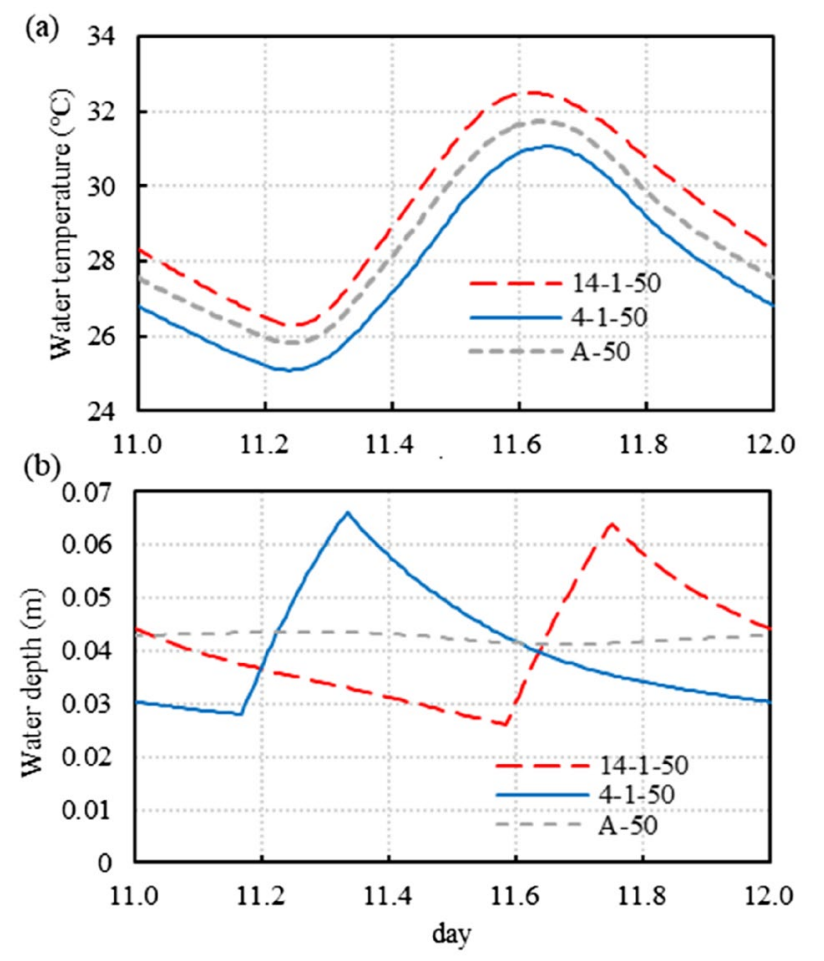

Fig. 10 Changes in water temperature of 14-1-50, 4-1-50, and A-50 for Case 3

\section{Effect of water management on water temperature distribution}

\section{Effect of irrigation water volume on paddy water temperature}

The different water temperature distributions between cases in our simulation (Fig. 5) show different effect of water management on paddy water temperature depending on the management model, suggesting that the water temperature in a paddy field can be controlled, to some extent, via water management.

A comparison of water temperature distribution under flowing irrigation with $50 \mathrm{~mm} \mathrm{~d}^{-1}$ and normal irrigation with $15 \mathrm{~mm} \mathrm{~d}^{-1}$ indicates that flowing irrigation increases the extent and magnitude of temperature effects. The water temperature gradient was observed even at the outlet under flowing irrigation, while it was only observed within approximately half of the field under a normal irrigation rate (Fig. 5). Nishida et al. (2016) conducted field experiments on water temperature distribution under flowing irrigation with various irrigation rate conditions and indicated that a large amount of cool water is required to effectively lower the paddy water temperature by flowing irrigation. Our numerical simulation confirmed the results of Nishida et al. (2016). These results suggest that a large amount of cool or 
hot irrigation water is essential for significantly decreasing or increasing the water temperature by water management, respectively. Therefore, the effect of water management on water temperature in paddy fields is essentially determined by the available irrigation water temperature and amount.

\section{Effect of irrigation duration, interval, and timing on paddy water temperature}

Although the effect of water management is fundamentally limited by the available irrigation water temperature and amount, the water temperature distribution can be controlled to some extent by manipulating the irrigation interval, duration, and timing, even if the available irrigation water conditions are the same. In fact, our numerical simulation demonstrated that the flowing irrigation model can be improved by changing such water management conditions.

A comparison of water temperature distribution under different irrigation intervals and durations (Fig. 11) indicated that lengthening the irrigation interval and shortening the irrigation duration stabilizes the time averaged temperature gradient across a field. Since an increase in irrigation rate increases the area (or distance from the inlet) where irrigation water affects temperature (Nishida et al. 2018), increasing the irrigation rate by lengthening the irrigation interval and shortening the irrigation duration increases the area and distance influenced by irrigation water (e.g., comparison of A-50, N-1-50, N-3-50, and 4-1-50 of Case 1 in Fig. 3), resulting in smaller temperature gradient in the field (Fig. 7). Furthermore, because the effects decrease after the end of irrigation (Figs. 3 and 7), the time averaged temperature gradient further decreases with the lengthening of the irrigation interval and shortening of the irrigation duration (Fig. 7). Consequently, lengthening the irrigation interval and shortening the irrigation duration results in the stabilization of the water temperature distribution.

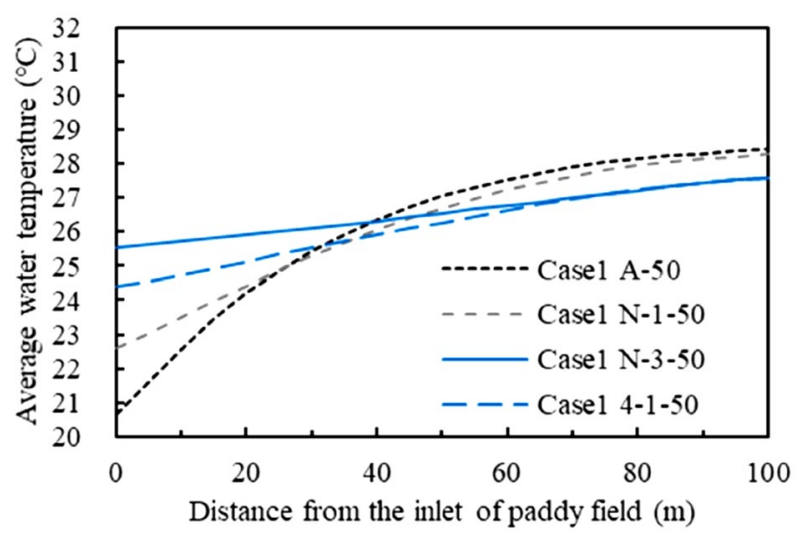

Fig. 11 Comparison of water temperature distribution under different irrigation intervals and durations with the same average irrigation rate
Furthermore, because the difference between irrigation water and equilibrium temperature varies with time, the effect of irrigation inflow changes with the irrigation timing (Figs. 8 and 9). For example, because the temperature difference was greater during daytime than nighttime in Case 1, water temperature near the inlet was lower under daytime irrigation than under nighttime irrigation (Fig. 8).

The results of Case 3 show that the equilibrium water temperatures of conventional irrigation were similar between daytime and nighttime application, while those of short-duration irrigation at pre-dawn and midday irrigation were lower and higher, respectively (Table 3). A similar tendency was observed in the water temperature near the outlet in Cases 1 and 2 (Fig. 5, Table 3). The temperature difference between short-duration and conventional irrigation suggests the effectiveness of short-duration irrigation for water temperature control, implying that the shortduration irrigation enhances water conservation.

The variations in water temperature and depth for shortduration irrigation in Case 3 (Fig. 10) indicate that irrigation during the time of the lowest paddy water temperature, which increased water depth during pre-dawn to midday, decreased the equilibrium water temperature; conversely, irrigation during the time of the highest water temperature, which increased water depth after midday, increased the equilibrium water temperature. Because increases in water depth increase the heat capacity of paddy water and decrease water temperature change (Nishida et al. 2018), an increase in water depth by irrigation at predawn suppresses the increase in paddy water temperature from pre-dawn to midday. Meanwhile, irrigation at midday suppresses the fall in temperature from midday to pre-dawn. However, although conventional irrigation also affected water depth trends (Fig. 2), the difference in the equilibrium temperature was low (Fig. 8), because the conventional irrigation (half-day or all day) affects both durations of water temperature increase (pre-dawn to midday) and decrease (midday to pre-dawn). Therefore, shorttime irrigation around pre-dawn or midday is effective in decreasing or increasing the equilibrium water temperature, respectively. Because this effect occurred regardless of the irrigation water temperature (Fig. 5), water temperature control by changing water depth is applicable under various irrigation water temperature conditions. Although such short- duration irrigation is difficult under conventional water management, the use of ICT water management, which can irrigate remotely and automatically, enables this management model, resulting in effective control of the equilibrium temperature.

The results suggest that the water temperature distribution can be altered by changing irrigation duration, interval, and timing, and the use of ICT in water management facilitates such activities. 


\section{Optimal water management}

Because irrigation water temperature significantly influences the water temperature distribution, the optimal management depends on the irrigation water temperature (Table 3). The ideal water management for a given case will vary depending on the purpose of irrigation (whether the water temperature is to be lowered or raised) and the irrigation water temperature conditions (negative or positive temperature difference from the equilibrium temperature).

In addition, because the effects of water management on the spatial average, maximum, and minimum water temperature and the variation differ depending on the water management method, the optimal water management method differs depending on which temperature is considered important. For example, comparing N-1-50 and N-3-50 (Table 3), the average water temperature and the minimum water temperature were lower in $\mathrm{N}-1-50$, but the variation and maximum water temperature in the paddy field were lower in $\mathrm{N}-3-50$. For the growth of rice, a large variation in water temperature (typically extremely low temperature near the inlet, such as A-15 and A-50 in Case 1) is generally unfavorable because it delays rice growth near the inlet (Wada 1992). In fact, low temperature damage due to inflow of cool water is often a challenge in rice cultivation in the northern areas of Japan (Wada 1992). For example, Wada (1992) reported that the yield of rice decreased when the average water temperature, 40 to 5 days before rice's heading date, was less than 24-26 ${ }^{\circ} \mathrm{C}$. Therefore, it is preferable that the water temperature variation is as small as possible to make the rice growth consistent. To reduce the time-average water temperature variation, short-time irrigation or irrigation with a long irrigation interval would be preferable. Since the quantitative relationship between water temperature and rice growth and yield remains nebulous (Wada 1992), further research is warranted to determine the effective water management method.

On the other hand, for other purposes, such as decreasing excess nitrogen runoff and greenhouse gas emissions from paddy fields, the spatial average, maximum, and minimum water temperatures may be more important than temperature variation across the field. To address such problems, the temperatures can be increased or decreased to within the ranges that do not affect rice growth. For example, denitrification, which decreases nitrate concentrations in runoff water from paddy fields, increases with an increase in soil temperature (Tan et al. 2018); greenhouse gas emissions such as $\mathrm{CO}_{2}$ and $\mathrm{CH}_{4}$ also increase with an increase in soil temperature (Rizzo et al. 2014). Such dynamics suggest that high water temperature could decrease nitrogen runoff, while low water temperature could decrease the greenhouse gas emissions. Therefore, to clarify the optimal water management method, it is necessary to clarify the target phenomena.
Optimal water management approaches can not only improve rice growth but also to reduce the negative impacts of human activities on the environment. Further research on the effects of water management on rice growth and nitrogen run-off and gas emissions in paddy fields are required. The numerical simulations applied in the present study based on the effects of water temperature on rice growth and the environment could facilitate the selection of ideal crop management methods and the prediction of their effects.

\section{Conclusions}

Numerical simulations were conducted to understand the effect of irrigation conditions on water temperature distribution in a paddy field. The following results were obtained:

(1) The effect of irrigation water temperature on the paddy water temperature was more significant close to the inlet. As the distance from the inlet increased, the paddy water temperature converged to an equilibrium determined not by irrigation water temperature, but by meteorological conditions and water depth. When the irrigation water temperature is lower (or higher) than the equilibrium water temperature, the paddy water temperature decreases (or increases) by irrigation.

(2) The extent and magnitude of the effects of irrigation water temperature increased with increasing irrigation volume. The effect of irrigation water temperature on paddy water temperature was limited to $\sim 50 \mathrm{~m}$ from the inlet using a normal irrigation volume (evapotranspiration + deep percolation); however, it was extended to the outlet by implementing flowing irrigation with a larger volume of irrigation water.

(3) Increasing the irrigation rate by lengthening the irrigation interval and shortening the irrigation duration reduced the amplitude of the average temperature gradient across the field.

(4) Short-duration irrigation during the time of the lowest paddy water temperature effectively lowered the equilibrium water temperature, while such irrigation during the time of highest water temperature effectively increased the equilibrium water temperature. The use of ICT water management, which can be used for remote and automatic irrigation, has the potential to enhance the effect of water management on temperature in paddy fields.

(5) The water management methods that most effectively increased or decreased the water temperature significantly depended on the irrigation water temperature. This means that the optimal water management method differs significantly depending on the meteorological conditions and irrigation water temperature conditions. 
To reveal effective water management techniques under various irrigation and meteorological conditions, further studies on the effect of water management on paddy water temperature under various conditions (meteorological factors, irrigation water temperature, and growth period), in addition to their effects on rice growth and the paddy field environments, are required. Numerical simulations using physical models similar to those applied in the present study facilitate the selection of management models and the prediction of their effects. Such studies would promote the effective use of ICT technologies in water management, potentially improve rice growth, and reduce the negative impacts of environmental challenges such as nitrogen runoff and greenhouse gas emissions.

\section{Appendices}

\section{Appendix A: Governing equations of the numerical model}

The governing equations of the numerical models of Nishida et al. (2021) are as follows: Horizontal water movement and changes in water depth in a paddy field are calculated using the water balance equation.

$\frac{\partial h}{\partial t}=-\frac{\partial Q}{\partial x}-P-E_{w}-E_{c}$

where $h$ is the water depth (m) in the paddy field, $t$ is the time (s), $Q(\geq 0)$ is the water flow rate per unit width in the paddy field $\left(\mathrm{m}^{2} \mathrm{~s}^{-1}\right), x$ is the horizontal distance $(\mathrm{m})$ from the inlet of the paddy field, $P$ is the percolation rate $\left(\mathrm{m} \mathrm{s}^{-1}\right)$ to deep soil, $E_{w}$ is the evaporation rate $\left(\mathrm{m} \mathrm{s}^{-1}\right)$ from water, and $E_{c}$ is the transpiration rate $\left(\mathrm{m} \mathrm{s}^{-1}\right)$.

Water and rice canopy temperatures were calculated using the heat balance equations of the paddy water and rice canopy. The heat balance equations are expressed by the double-source model of Kondo and Watanabe (1992) with the terms expressing heat convection due to horizontal water flow in a paddy field (Nishida et al. 2021) as follows:

$$
\begin{aligned}
f_{v} R_{\downarrow}+\left(1-f_{v}\right) \sigma T_{c}^{4}= & \sigma T_{w}^{4}+H_{w}+L E_{w}+G+C_{w} \frac{\partial h T_{w}}{\partial t} \\
& +C_{w} \frac{\partial Q T_{w}}{\partial_{w}}+C_{w}\left(P+E_{c}\right) T_{w},
\end{aligned}
$$

$\left(1-f_{v}\right)\left(R_{\downarrow}+\sigma T_{w}^{4}\right)=2\left(1-f_{v}\right) \sigma T_{c}^{4}+H_{c}+L E_{c}$

where $T_{c}$ and $T_{w}$ are the mean rice canopy and paddy water temperature $(\mathrm{K})$, respectively; $R_{\downarrow}$ is the incoming radiation $\left(\mathrm{Wm}^{-2}\right)$, including solar radiation $((1$-albedo $) \times$ solar radiation) and long-wave radiation from the sky; $f_{v}$ is the transmissivity of the rice canopy for radiation; $\sigma$ is the Stefan-Boltzmann constant $\left(5.67 \times 10^{-8} \mathrm{Wm}^{-2} \mathrm{~K}^{-4}\right) ; H$ and $L E$ are the sensible and latent heat flux $\left(\mathrm{Wm}^{-2}\right)$, respectively; subscripts $w$ and $c$ indicate heat flux from the paddy water to the atmosphere and from the rice canopy to the atmosphere, respectively; $G$ is the downward heat conduction flux $\left(\mathrm{Wm}^{-2}\right)$ from paddy water to the soil; and $C_{w}$ is the volumetric heat capacity of water $\left(4.184 \times 10^{6} \mathrm{Jm}^{-3} \mathrm{~K}^{-1}\right)$.

Soil temperature is calculated by vertical one-dimensional heat conduction-convection equation.

$C_{s} \frac{\partial T_{s}}{\partial t}=\lambda \frac{\partial^{2} T_{s}}{\partial z^{2}}-C_{w} \frac{\partial Q_{z} T_{s}}{\partial z}$,

where $T_{s}$ is the soil temperature $(\mathrm{K}), C_{s}$ is the volumetric heat capacity of the soil $\left(\mathrm{Jm}^{-3} \mathrm{~K}^{-1}\right), \lambda$ is the heat conductivity of soil $\left(\mathrm{Wm}^{-1} \mathrm{~K}^{-1}\right), z$ is the soil depth $(\mathrm{m})$ from the soil surface, and $Q_{z}$ is the downward water flux $\left(\mathrm{ms}^{-1}\right)$ in the soil.

Details of the heat flux calculations are described by Nishida et al. (2021) and the paper cited in Nishida et al. (2021).

\section{Appendix B: Calculation method}

The calculation procedure is similar to that of Nishida et al. (2021), but some procedures (procedures 1 and 6 described below) were modified for the numerical simulation of this study. Procedures 2-5 described below are the same as those described by Nishida et al. (2021). Discretized equations of the heat balance equations and a detailed explanation of the procedures are provided by Nishida et al. (2021).

(1) The finite difference equation of the water balance equation of a paddy field obtained by integrating Eq. (1) from the inlet $(x=0)$ to the outlet of the paddy field $(x=\mathrm{L})$ was solved to determine $h$ at the next time step.

$L \frac{h-h^{0}}{\Delta t}=Q_{\text {in }}-Q_{\text {out }}-\left(P+E_{w}+E_{c}\right) L$,

where $Q_{\text {in }}$ is the irrigation rate $\left(\mathrm{m}^{2} \mathrm{~s}^{-1}\right)$ per unit width in the paddy field, $Q_{\text {out }}$ is the surface runoff $\left(\mathrm{m}^{2} \mathrm{~s}^{-1}\right)$ from the outlet of the paddy field, $L$ is the length (m) between the inlet and outlet of the paddy field, and superscript 0 indicates the value at the previous time step.

$Q_{i n}$ and $P$ were obtained from the calculation conditions. $Q_{\text {out }}$ was calculated from $h^{0}$ using a weir function, as follows:

$$
\begin{aligned}
& Q_{\text {out }}=a\left(h^{0}-h_{w}\right)^{1.5} \quad h^{0} \geq h_{w} \\
& Q_{\text {out }}=0 \quad h^{0}<h_{w}
\end{aligned}
$$


where a is an empirical constant $\left(\mathrm{m}^{0.5} \mathrm{~s}^{-1}\right)$, and $h_{w}$ is the weir height $(\mathrm{m})$ from the soil surface at the outlet. Because $E_{w}$ and $E_{c}$ in Eqs. (5) were not solved yet in this procedure, those at the previous iteration level were used. Using these values, $h$ at the next time step was solved.

Then, $Q(x)$ at the boundary between nodes is calculated using Eq. (7).

$Q_{(i)}=Q_{(i-1)}-\left(\frac{h-h^{0}}{\Delta t}+P+E_{w(i)}+E_{c(i)}\right) \delta x_{(i)}$

where the subscript $i$ indicates the horizontal node number $(i=1$ to $n x)$, and $\delta x(i)$ is the horizontal length of node $i, Q_{(i)}$ is the $Q(x)$ at $x=x_{(i)}+\delta x_{(i) / 2}$. Note that in the work of Nishida et al. (2021), $E_{w(i)}$ and $E_{c(i)}$ in Eq. (7) were assumed to be zero, but this study considered these factors.

(2) Using $h$ and $Q_{(i)}$ with the soil surface temperature $T_{s(j=1)}$ in the previous iteration, the heat balance equations (2) and (3) were simultaneously solved using the Newton-Raphson procedure to obtain $T_{w}$ and $T_{c}$. Then, evapotranspiration rates $\left(E_{w(i)}\right.$ and $\left.E_{c(i)}\right)$, downward heat conduction flux of $G_{(i)}$, and downward heat convection flux $\left(\mathrm{C}_{w}\left(\mathrm{P}+E_{c(i)}\right) \mathrm{T}_{w(i)}\right)$ were calculated.

(3) The downward heat fluxes were given as an upper boundary condition of the soil heat balance equation in Eq. (4); the soil temperature profiles were determined. The implicit finite difference method was used for the calculations.

(4) Procedures 2 and 3 were repeated until the difference of $T_{\mathrm{s}(j=1)}$ at the previous iteration and solved from procedure 3 became lower than iteration criterion.

(5) Procedures 2 to 4 of next space node $(i+1)$ were performed.

(6) Using the calculated $E_{w(i)}$ and $E_{c(i)}$, Eq. (5) is solved again, and $h$ at the next iteration level was obtained. Until the difference of $h$ at the previous iteration and solved from procedure 1 became lower than the iteration criterion, procedures 1-5 were repeated.

Supplementary Information The online version contains supplementary material available at https://doi.org/10.1007/s10333-021-00884-1.

Acknowledgements This work was supported by the Japan Society for the Promotion of Science (JSPS) KAKENHI (Grant number 19H03071). We would like to thank Mr. I. Yoshikawa, who owns a rice paddy field where field measurements were taken.

Open Access This article is licensed under a Creative Commons Attribution 4.0 International License, which permits use, sharing, adaptation, distribution and reproduction in any medium or format, as long as you give appropriate credit to the original author(s) and the source, provide a link to the Creative Commons licence, and indicate if changes were made. The images or other third party material in this article are included in the article's Creative Commons licence, unless indicated otherwise in a credit line to the material. If material is not included in the article's Creative Commons licence and your intended use is not permitted by statutory regulation or exceeds the permitted use, you will need to obtain permission directly from the copyright holder. To view a copy of this licence, visit http://creativecommons.org/licenses/by/4.0/.

\section{References}

Inoue K (1985) A simulation model for micrometeorological environment in rice field. J Agric Meteorol 40:353-360. https://doi.org/ 10.2480/agrmet.40.353 (in Japanese with English abstract)

Kim W, Arai T, Kanae S, Oki T, Musiake K (2001) Application of the simple biosphere model ( $\mathrm{SiB} 2)$ to a paddy field for a period of growing season in GAME-Tropics. J Meteorol Soc Jpn 79:387400. https://doi.org/10.2151/jmsj.79.387

Kondo J, Watanabe T (1992) Studies on the bulk transfer coefficients over a vegetated surface with a multilayer energy budget model. J Atmos Sci 49:2183-2199. https://doi.org/10.1175/15200469(1992)049\%3c2183:SOTBTC\%3e2.0.CO;2

Kondo J (1994) Mizukannkyo no Kishogaku. Asakura Publishing Co., Ltd., pp 86-92 (in Japanese)

Liu X, Xu J, Liu B, Wang W, Li Y (2019) A novel model of water-heat coupling for water-saving irrigated rice fields based on water and energy balance: Model formulation and verification. Agric Water Manag 223:105705. https://doi.org/10.1016/j.agwat.2019.105705

Maruyama A, Kuwagata T (2008) Diurnal and seasonal variation in bulk stomatal conductance of the rice canopy and its dependence on developmental stage. Agric for Meteorol 148:1161-1173. https://doi.org/10.1016/j.agrformet.2008.03.001

Maruyama A, Nemoto M, Hamasaki T, Ishida S, Kuwagata T (2017) A water temperature simulation model for rice paddies with variable water depths. Water Resour Res 53:10065-10084. https://doi.org/ 10.1002/2017WR021019

Mitsuyasu M, Nishida K, Ninomiya Y, Yoshida S, Nomura M (2020) Effect of water management techniques on water and soil temperature in paddy field during rice ripening period. Water Land Environ Eng 88:805-808 (in Japanese)

Miyasaka A, Nakajima T, Maruyama A, Wakiyama Y (2011) Effects of lower water temperature, by water streaming treatment during ripening stage, on sheath blight disease and white immature kernels in rice. Kyushu Pl Prot Res 57:1-6 (in Japanese)

Morita S (2008) Prospect for developing measures to prevent high-temperature damage to rice Grain ripening. Jpn J Crop Sci 77:1-12 (in Japanese with English abstract)

Morita S, Wada H, Matsue Y (2016) Countermeasures for heat damage in rice grain quality under climate change. Plant Prod Sci 19:1-11. https://doi.org/10.1080/1343943X.2015.1128114

Nagahata H, Nakamura K, Ino M, Kuroda A, Hashimoto Y (2005) The cultivation management to make the occurrence of the milky white kernel and the cracked rice reduce under the high temperature during the ripening period. Boll Ishikawa Agric Res Cent 26:1-10 (in Japanese with English abstract)

Nishida K, Uo T, Yoshida S, Tsukaguchi T (2015) Effect of water depth, amount of irrigation water, and irrigation timing on water temperature in paddy field during continuous irrigation with cool running-water. Transact Jpn Soc Irrigat Drain Rural Eng 300:185194. https://doi.org/10.11408/jsidre.83.I_185 (in Japanese with English abstract)

Nishida K, Yoshida S, Shiozawa S (2018) Theoretical analysis of the effects of irrigation rate and paddy water depth on water and leaf temperatures in a paddy field continuously irrigated with running water. Agric Water Manag 198:10-18. https://doi.org/10.1016/j. agwat.2017.11.021 
Nishida K, Yoshida S, Shiozawa S (2021) Numerical model to predict water temperature distribution in a paddy rice field. Agric Water Manag 245:106553. https://doi.org/10.1016/j.agwat.2020.106553

Nishida K, Ninomiya Y, Uo T, Yoshida S, Shiozawa S (2016) Relationship between irrigation conditions and distribution of paddy water temperature under continuous irrigation with running water. Transact Jpn Soc Irrigat Drain Rural Eng 303:I_391-I_401. https://doi.org/10.11408/jsidre.84.I_391 (in Japanese with English abstract)

Rizzo A, Boano F, Revelli R, Ridolfi L (2014) Decreasing of methanogenic activity in paddy fields via lowering ponding water temperature: A modeling investigation. Soil Biol Biochem 75:211-222. https://doi.org/10.1016/j.soilbio.2014.04.016

Saptomo SK, Nakano Y, Yuge K, Haraguchi T (2004) Observation and simulation of thermal environment in a paddy field. Paddy Water Environ 2:73-82. https://doi.org/10.1007/s10333-004-0047-2

Sharifi H, Hijmans RJ, Hill JE, Linquist BA (2018) Water and air temperature impacts on rice (Oryza sativa) phenology. Paddy Water Environ 16:467-476. https://doi.org/10.1007/s10333-018-0640-4

Shimono H, Hasegawa T, Iwama K (2002) Response of growth and grain yield in paddy rice to cool water at different growth stages. Field Crops Res 73:67-79. https://doi.org/10.1016/S03784290(01)00184-8

Suzuki S, Maruyama A, Wakasugi K (2020) Field verification of water management technology for high-temperature and low-temperature injury on paddy field with ICT water. Land Environ Eng 88:817-820 (in Japanese)

Tan X, Shao D, Gu W (2018) Effects of temperature and soil moisture on gross nitrification and denitrification rates of a Chinese lowland paddy field soil. Paddy Water Environ 16:687-698. https://doi.org/ 10.1007/s10333-018-0660-0

Tashiro T, Wardlaw IF (1991) The effect of high temperature on kernel dimensions and the type and occurrence of kernel damage in rice. Aust J Agric Res 42:485-496. https://doi.org/10.1071/AR9910485

Terashima K, Saito Y, Sakai N, Watanabe T, Ogata T, Akita S (2001) Effects of high air temperature in summer of 1999 on ripening and grain quality of rice. Jpn J Crop Sci 70:449-458 (in Japanese with English abstract)

Tomosho T, Yamashita T (2009) Problems and future directions of agricultural water management as measures against grain damage under high temperatures during ripening of rice. Tech. Rep. Natl. Inst. Rural Eng Jpn:131-138 (in Japanese with English abstract)

Wada Y, Oozeki F, Kobayashi T, Kumekawa H (2013) Effects of cool water irrigation on reduction of grain quality of rice by high air temperatures during the ripening period. Jpn J Crop Sci 82:360 368 (in Japanese with English abstract)

Wada S (1992) Suito no reigai. Yokendo Co., Ltd., pp 216-239 (in Japanese)

Wakasugi K, Suzuki S (2017) Remote automatic operation system using ICT for on-farm water management in rotational paddy fields. Water Land Environ Eng 85:11-14. (in Japanese). https:// doi.org/10.11408/jjsidre.85.1_11

Yoshida K, Azechi I, Kuroda H (2013) Application of two layer heat balance model for calculation of paddy thermal condition. J Jpn. Soc Civ Eng B1 69:I_139-I_144. https://doi.org/10.2208/jscejhe. 69.I_139 